\title{
Estudios discursivos del ethos en la telenovela costumbrista colombiana*
}

\author{
LUCÍA BUSTAMANTE VÉLEZ** \\ lucia.bustamante@uptc.edu.co
}

Recepción: 12 de febrero de 2015

Aprobación: 27 de marzo de 2015

Forma de citar este artículo: Bustamante Vélez, L. (2016). Estudios discursivos del ethos en la telenovela costumbrista colombiana. Cuadernos de Lingüística Hispánica, (27), 137-156.

\footnotetext{
* Artículo de investigación. Expone resultados de la tesis doctoral titulada "Construcción discursiva del ethos en la telenovela costumbrista colombiana".

** Comunicadora Social-Periodista; Especialista en Didáctica Universitaria; Magíster en Educación, Universidad de Antioquia, Colombia; doctoranda en Lenguaje y Cultura, Universidad Pedagógica y Tecnológica de Colombia, Colombia. Grupo de investigación Corporación "Si Mañana Despierto" para la Creación e Investigación de la Literatura y las Artes. Docente de la Escuela de Idiomas de la Universidad Pedagógica y Tecnológica de Colombia, Colombia.
} 


\title{
Resumen
}

El presente trabajo constituye un avance de la investigación "Construcción discursiva del ethos en la telenovela costumbrista colombiana". Como objeto de análisis, específicamente se privilegia Café con aroma de mujer por considerarla una telenovela representativa del tipo costumbrista en Colombia y por su gran impacto social y cultural en el país y en el extranjero. Se pretende caracterizar las imágenes de sí que construye el locutor-enunciador en el seriado, mediante las cuales ejerce una gran fuerza persuasiva sobre la audiencia. Las bases teóricas y metodológicas de la investigación que se proponen están ancladas en un enfoque histórico-discursivo y dialógico del lenguaje (Bajtín, 1982) y, desde este, en la Dinámica Social Enunciativa de Martínez (2001a, 2001b, 2005, 2013). Como categorías de análisis se tomaron, en el campo semántico: temas y tópicos (Van Dijk, 2003; Martínez, 2005) y en el ámbito enunciativo: situaciones de comunicación y de enunciación, tonalidades y dimensiones. El análisis de la construcción del ethos de la protagonista a partir del tema de la educación permite concluir que desde este personaje se movilizan imágenes asociadas a diversos ethos - de autoridad, de superación, de competencia-, que rescatan y refuerzan aspectos tradicionales y costumbristas de la cultura paisa.

Palabras clave: identidad y discurso, discurso y telenovela, ethos discursivo, ethos y telenovela, retórica y cultura.

\section{Discursive studies on the ethos of Colombian costumbrist soap operas}

\begin{abstract}
This paper constitutes the first part of the research project "Discursive construction of the ethos of Colombian costumbrist soap operas". As object of analysis, we specifically priviledged Café con aroma de mujer [Woman Scented Coffee], because we consider it to be a representative costumbrist Colombian soap opera and because of the great social and cultural impact it has had in Colombia as well as in other countries. We aspire to characterize the different forms of self-image constructed by the narrator of the show, given the fact that these images exert great persuasive force over the audience. This research is theoretically and methodologically based on a historical, discursive and dialogical standpoint of language (Bajtín, 1982) and, in the social-enunciative dynamics of Martínez
\end{abstract}


(2001 a, 2001b, 2005, 2013). As categories of analysis we identified: themes and topics in the semantic field (Van Dijk, 2003, Martínez, 2005), and situations of comunication and enunciation, tonalities and dimensions in the enunciative field. Starting from the topic of education, the analysis of $e$ thos constructions of the main character allow us to conclude that through this character images related to a series of ethos - related to authority, success, and competence- are disseminated. These images revive and reinforce the traditionality and costumbrism of the paisa regional culture.

Key words: identity and speech, speech and soap operas, discursive ethos, ethos and soap operas, retoric and culture.

\section{Études discursives de l'ethos dans le roman coutumier colombien}

\section{Résumé}

Ce travail constitue une avance de la recherche «Construction discursive du ethos dans le roman coutumier colombien». En tant qu'objet d'analyse, de manière spécifique, nous privilégions Café avec arôme de femme pour le considérer un roman représentatif du type coutumier en Colombie et pour son grand impact social et culturel dans le pays et à l'étranger. Nous prétendons caractériser les images de soi qui construit l'interlocuteurénonciateur dans le sérié, à travers lesquelles il exerce une grande forcé persuasive sur l'audience. Les bases théoriques et méthodologiques de la recherche que nous proposons, sont ancrées dans une approche historico-discursive et dialogique du langage. (Bajtín, 1982) et, à partir de cela, dans la Dynamique Sociale Enonciative de Martínez (2001a, 2001b, 2005, 2013). En tant que catégories d'analyse, nous avons pris, dans le champ sémantique : sujet et clichés (Van Dijk, 2003; Martínez, 2005) ; et dans le domaine énonciatif : situations de communication et d'énonciation, tonalités et dimensions. L'analyse de la construction de l'ethos du protagoniste à partir du sujet de l'éducation, permet de conclure qu'à partir de ce personnage, on mobilise des images associées à divers ethos -d'autorité, de dépassement, de compétence-, qui rachètent et renforcent des aspects traditionnels et coutumiers de la culture paisa.

Mots clés: identité et discours, discours et roman, ethos discursif, ethos et roman, rhétorique et culture. 


\section{Estudos discursivos do ethos na telenovela costumbrista colombiana}

\section{Resumo}

0 presente trabalho constitui um avanço da pesquisa "Construcción discursiva del ethos en la telenovela costumbrista colombiana". Como objeto de análise, especificamente privilegiamos Café con aroma de mujer por considerá-la uma telenovela representativa do tipo costumbrista na Colômbia e por seu grande impacto social e cultural no país e no estrangeiro. Pretendemos caracterizar as imagens de si mesmo que constrói o locutorenunciador no seriado, mediante as quais exerce uma grande força persuasiva sobre a audiência. As bases teóricas e metodológicas da pesquisa que propomos estão ancoradas em um enfoque histórico-discursivo e dialógico da linguagem (Bajtín, 1982) e, desde este, na Dinâmica Social Enunciativa de Martínez (2001a, 2001b, 2005, 2013). Como categorias de análise, tomamos no campo semântico: temas e tópicos (Van Dijk, 2003; Martínez, 2005) e no âmbito enunciativo: situações de comunicação e de enunciação, tonalidades e dimensões. A análise da construção do ethos da protagonista a partir do tema da educação nos permite concluir que desde esta personagem se mobilizam imagens associadas a diversos ethos -de autoridade, de superação, de competência-, que resgatam e reforçam aspectos tradicionais e costumbristas da cultura paisa.

Palavras chave: identidade e discurso, discurso e telenovela, ethos discursivo, ethos e telenovela, retórica e cultura. 


\section{Introducción}

El impacto de la telenovela en la formación sociocultural de la audiencia, y su carácter persuasivo, ofrecen a los estudios del ethos un terreno fértil y atrayente, dado que en el desarrollo de esta se establecen relaciones entre los sujetos Yo (enunciador) y Tú (enunciatario), en las que el último queda cautivo ante la verosimilitud que el primero confiere al relato. Esto sucede porque, en el proceso discursivo, los atributos (ethos) que el locutor muestra a su auditorio (enunciatarios), es decir, lo que quiere ser para ellos por medio de las imágenes de los personajes (enunciadores), se vehiculan a través del discurso.

Café con aroma de mujer es una telenovela colombiana de tipo costumbrista que acaparó no solo una audiencia local y nacional sino internacional. La mayor fuerza persuasiva de un discurso está en el ethos, según lo plantea la antigua retórica (Aristóteles, 1999) y lo corrobora la nueva (Maingueneau, 2005, 2009), (Amossy, 1999), (Ducrot, 1984), (Charaudeau, 1983, 2005), (Martínez, 2001, 2005, 2013). De ahí que, el interés de la presente investigación se enfoque en dar cuenta de la dinámica social enunciativa construida en este discurso televisivo para atraer, de manera tan decisiva, la atención de la audiencia.

En consideración a lo anterior, se busca caracterizar, a partir de la Dinámica Social Enunciativa (Martínez), las imágenes de sí que se construyen en la telenovela costumbrista colombiana Café con aroma de mujer y que permiten dar cuenta de la fuerza persuasiva que ejerce el locutor en este discurso.

El problema de investigación está relacionado con las imágenes de sí, del sujeto integral que exhibe la telenovela costumbrista colombiana utilizando como referente el lenguaje y la cultura regional, en particular una telenovela emblemática como Café con aroma de mujer.

Planteamos la hipótesis según la cual las estrategias discursivas, utilizadas en la construcción de la diversidad de ethos exhibida en la telenovela colombiana de tipo costumbrista, ejercen una gran fuerza persuasiva en la audiencia.

\section{Fundamentación teórica}

El estudio que se propone tiene sus bases en el Análisis del Discurso con una concepción dialógica del lenguaje, cuyos fundamentos están en Bajtín y Martínez. Según la teoría bajtiniana, todo discurso es dialógico, en la medida en que el hablante es un 
interlocutor que cuenta con la presencia de ciertos enunciados anteriores, suyos y ajenos, con los cuales su enunciado establece relaciones y se apoya en ellos, los problematiza o los supone conocidos por su oyente. Es esta alusión a un enunciado ajeno, así sea ligera, la que le confiere al discurso un carácter dialógico.

También se toman aportes sobre la enunciación y los enunciados (Baitín, Ducrot, Kerbrat-Orecchioni); la retórica (noción de ethos planteada por Aristóteles, Barthes y por algunos analistas del discurso francés: Perelman y Olbrechts-Tyteca, Charaudeau, Maingueneau, Ducrot, Amossy, Plantin); el análisis crítico del discurso (sobre los conceptos de cultura, identidad, ideología, representación social, lugares comunes, estereotipos, desarrollados en García Canclini, UNESCO, Martín-Barbero, Brunner, Zecchetto, Van Dijk, Amossy, Wodak y Meyer, Fairclough y Wodak); el discurso narrativo, particularmente el novelesco, televisivo, telenovelesco y costumbrista (Bajtín, Bettetini, Adrianzén, MartínBarbero), y de la semiótica social (a partir de la noción de multimodalidad en Kress y van Leeuwen Kress).

Para los fines investigativos, se asume una posición epistemológica con dicha concepción dialógica (Baitin, Ducrot, Maingueneau, Martínez), en tanto consideramos que somos construidos por y en el lenguaje en permanente interacción con los otros. La perspectiva dialógica del discurso permite entender las fuerzas enunciativas instauradas en el enunciado y la manera como los sujetos discursivos se construyen en él, a través de las diversas formas de manifestación que toma el discurso. Desde esta visión, el ser humano construye discursivamente su ethos solo en el enunciado. Así mismo, la comprensión de las fuerzas sociales establecidas en el enunciado da cuenta de cómo un discurso dado, e históricamente situado, construye saberes colectivos, además de su impacto en la cultura.

\subsection{Estudios sobre el ethos discursivo}

El ethos, el pathos y el logos hacen parte de la trilogía aristotélica de los medios de prueba de la Retórica. En Aristóteles(1999) la noción de ethos remite a dos acepciones: una que designa las virtudes morales ${ }^{1}$ (prudencia, virtud y benevolencia) que dan credibilidad al orador, y otra que implica una dimensión social en tanto el orador convence expresándose de manera apropiada a su carácter y tipo social (Charaudeau y Maingueneau, 2005, p. 246). Pero es Barthes (1974), al estudiar el ethos en la antigua retórica, quien establece su característica esencial al definirlo como los rasgos de carácter que el orador debe mostrar al auditorio (sin importar su sinceridad) para causar buena impresión.

1 Al respecto, téngase en cuenta la afirmación que hace Soulez (2009) al aclarar que aunque los "atributos" del orador sean expresados en términos de moralidad, la noción de ethos alude al carácter moral que se manifiesta en el discurso y no al verdadero carácter moral del orador, lo cual concuerda también con lo planteado por Martínez (2005). 
Maingueneau (2009) retoma la noción de ethos retórico y la instala en la enunciación como parte de la construcción de la identidad. El ethos es para este autor una corporalidad, una instancia enunciativa caracterizada por tener un "cuerpo" y un "carácter" específicos (e independientes del cuerpo del hablante), a los cuales se accede a través de una "voz", un "tono" presente en todo texto, sea oral o escrito, a los que está asociado. Ese enunciador encarnado cumple el papel de garante, fuente que legitima lo que es dicho. Esta noción atañe no solo a lo dicho sino al conjunto de determinaciones físicas y psíquicas relacionadas por las representaciones colectivas con el personaje del enunciador. Así, la figura del garante debe ser construida por el lector a partir de los indicios textuales de diversos órdenes, el cual le atribuye un carácter (rasgos psicológicos) y una corporalidad (complexión física, manera de vestirse, de moverse) captados a través de un comportamiento global.

El carácter y la corporalidad del garante provienen del conjunto difuso de representaciones sociales valorizadas o desvalorizadas (estereotipos) sobre las cuales la enunciación se apoya y pueden ser reforzadas o transformadas. En este sentido, el universo de sentido entregado por el discurso es impuesto tanto por el ethos como por las ideas que comunica, ideas que se presentan a través de una manera de decir y remiten a una manera de ser, a la participación imaginaria en una vivencia (Maingueneau, 2009, p. 92).

Para Ducrot (1984), el ethos constituye la imagen de sí que construye el locutor en su discurso para ejercer influencia sobre su alocutario, es decir, la instancia discursiva del locutor, y no el sujeto hablante (empírico). Con esta distinción el autor rompe con la unicidad del sujeto. El autor afirma que es en el enunciado donde se construyen los sujetos discursivos Ethos (imagen del Yo) y Pathos (imagen del Tú). El análisis de este locutor L, permite ligar el ethos tanto a la inventio (elección de las ideas y emociones), como a la elocutio (elección de las palabras) y a la actio (cadencia, entonación).

Martínez (2001a, 2001b) en sus estudios contempla el Ethos del locutor de una manera integral, al considerar su análisis conjuntamente con los sujetos discursivos Pathos y Ratio en el escenario discursivo, el cual denomina LOGOS. Según esta teoría, el Ethos así conceptualizado puede ser visualizado a través de voces, tonalidades, dimensiones, jerarquías sociales, problemáticas, temas, valores, costumbres, etc., que se dejan leer en el enunciado y permiten dar cuenta de la identidad del sujeto discursivo ético, emotivo y racional. Pero también estos permiten construir el ethos en el discurso mismo desde las diferentes dimensiones (ética, emotiva, racional). 


\section{Contexto histórico de Café con aroma de mujer}

La telenovela Café con aroma de mujer fue emitida entre 1994 y 1995. El escenario social en el cual se desarrolla la trama refleja las condiciones sociales de los años 80 y mediados de los 90, en torno a los protagonistas de la industria cafetera colombiana. $\mathrm{Si}$ bien, el tema central de la telenovela es el amor, su trama recrea situaciones y problemáticas sociales de la época, como el desfalco financiero por parte de algunos miembros de familias colombianas prestigiosas, el tráfico de personas, y otras que se desarrollan en la cotidianidad de las familias involucradas en el mercado cafetero y dan cuenta de tradiciones, costumbres, contradicciones sociales e ideológicas a partir de la lucha de clases, la situación social y económica del recolector, el proceso de producción, recolección, comercialización, distribución y fluctuaciones del café, los valores en pugna, el tráfico de influencias, entre otras.

\section{Metodología}

La investigación fue de corte cualitativo con un enfoque enunciativo de tipo dialógico. Metodológicamente, y de acuerdo con los objetivos planteados, a partir de la Dinámica Social Enunciativa, se expuso el principio dialógico contenido en la telenovela (Bajtín, 1982; Ducrot, 1984), así como las relaciones de fuerza social, a partir del reconocimiento de la situación de comunicación; la identificación de las valoraciones y puntos de vista propuestos e integrados en el enunciado por el locutor (polifonía enunciativa), desde la situación de enunciación; el reconocimiento de los actos evaluativos en relación con los puntos de vista y el peso jerárquico adjudicados por el locutor, a través de la identificación de las tonalidades y, por último, la exploración de la identidad del sujeto discursivo a partir de la focalización de las dimensiones ética, emotiva y racional.

Debido a la extensión del reparto, y por razones de delimitación, se enfocó el análisis en los personajes: Teresa Suárez (Gaviota), Sebastián Vallejo, Octavio Vallejo y Cecilia de Vallejo, a partir de los cuales se pudo dar cuenta de la construcción de una diversidad de ethos que exponen la caracterización de personajes y valores que la telenovela costumbrista busca reforzar o transformar (Maingueneau, 2009) y desde los cuales el locutor-autor persuade a la audiencia.

Para el análisis se tomó como categorías axiales, en el campo semántico: temas y tópicos (Van Dijk, 2003) y como categorías centrales, en el campo socio-enunciativo: situaciones de comunicación y de enunciación, tonalidades y dimensiones (Martínez, 2005). Estos aspectos se encuentran fusionados en la Dinámica Social Enunciativa (DSE) con la noción retórica de ethos y sus diversas manifestaciones; con el análisis crítico 
del discurso, mediante los conceptos de ideología, identidad, representaciones sociales, lugares comunes, estereotipos, etc.; con el lenguaje narrativo, particularmente el de la telenovela y el televisivo y, finalmente, con el discurso multimodal y sus manifestaciones semióticas.

En torno a los personajes seleccionados, se privilegiaron temas como la educación, el café, la religión, la familia, en una confrontación permanente de valores-contravalores y puntos de vista, desde los cuales se quiere rescatar y reforzar los aspectos positivos de las costumbres de la región con respecto a la idiosincrasia paisa y cafetera.

\subsection{Criterios en la selección del corpus}

Dado que se trata de una telenovela de tipo costumbrista, a partir de la cual se busca reproducir, reforzar o transformar ciertos valores y comportamientos de una cultura particular (Maingueneau, 2009), se delimitó el análisis, entre una diversidad de aspectos, a temas como educación, familia, café, folclor, expuestos a través de personajes centrales como Gaviota-Carolina, Sebastián, Iván, Octavio y Cecilia de Vallejo. Se considera que, desde los diversos temas y personajes seleccionados, en una confrontación permanente de valores-contravalores, puntos de vista, estereotipos, etc., se pretende rescatar y valorizar los aspectos positivos de las costumbres de la región con respecto a la idiosincrasia paisa y cafetera, y que, desde esta valoración, se puede identificar la construcción de una multiplicidad de ethos por medio de los cuales el locutor busca persuadir a la audiencia.

Teniendo en cuenta lo anterior, el corpus está constituido por varios diálogos referidos a temas como la educación, la familia, el café y el folclor. En este artículo se hace referencia en particular al tema de la educación.

\section{Análisis del corpus}

\subsection{Dinámica social enunciativa de Café y construcción de ethos}

Por ser de corte costumbrista, en la telenovela Café predominan las descripciones de personajes y modos de vida de la región cafetera paisa, con las cuales se quiere valorizar sus aspectos positivos, en permanente pugna con contravalores que se ponen en entredicho.

Entre los aspectos que contribuyen a preservar y reforzar los valores y costumbres de dicha cultura en este relato audiovisual está la educación, dispositivo fundamental en el empuje y altruismo de la cultura paisa. El aspecto educativo expuesto en la obra hace evidente, por un lado, el esfuerzo y la constancia hacia el estudio, con el propósito de resaltar la educación de las clases populares como un aspecto loable, positivo y alcanzable. 
Y, por otro, hace un cuestionamiento a las desigualdades educativas entre unas clases y otras y a su consecuente inequidad.

Con respecto al tema de la educación, se toman algunas unidades relevantes relacionadas con el personaje de Gaviota que tienen que ver con el deseo de superación a través del estudio que ella demuestra durante su carrera de ascenso social (recolectora, recepcionista, secretaria, asistente de gerencia, subgerente, subdirectora). En los textos seleccionados el autor expresa una intención de exaltar la educación como uno de los pilares sobre los que se legitima esta cultura, a través de los diversos ethos que exhiben los sujetos discursivos.

Dado que el presente artículo constituye un avance de la investigación, y por razones de espacio, se ha seleccionado el siguiente texto para ilustrar el análisis:

(1) -Vea, aquí está la mesa todavía (dice Gaviota mientras procede a limpiarla).

(2) -Cómo así Gaviota ¡usted todavía baciendo tareas? ¡Usted ya está muy grande pa' eso!

(3)-¿Le parece? (responde Gaviota mientras se detiene un segundo para mirarlo)

(4) -Pues sí

(5) $-Y$ es que si no, pierdo la costumbre. Pues si pierdo la costumbre se me olvidan las letras, y si se me olvidan las letras se me olvida leer y escribir, y si se me olvida leer y escribir me voy a quedar recogiendo café toda la vida. Yo asi no me quiero quedar. Vea, a mi leer y escribir me va a servir mucho más que para recoger bultos de café. ¿Cómo la ve desde ahi Aurelio? (afirma Gaviota mientras organiza la habitación y mira a Aurelio una que otra vez con una actitud de convencimiento y seguridad. Mientras tanto, este la mira y la escucha parado en la puerta de la habitación, dándole vueltas con las manos nerviosamente a su sombrero).

(6) -Como diga doña Gaviota

\section{Situación de comunicación:}

La situación de comunicación alude al espacio discursivo semántico en el que se evidencian las relaciones de fuerza social, las relaciones de poder entre los sujetos discursivos. Estas relaciones pueden ser de tipo simétrico o asimétrico, según sea el tipo de relación jerárquica que se establece entre los sujetos discursivos, y definen los roles socioinstitucionales y discursivos que se representan en el enunciado. También, en la Situación de Comunicación (SC), se instaura la legitimidad del sujeto que asume la voz responsable 
que le corresponde en el género según el contrato social que el locutor establece con su interlocutor (Martínez, 2013).

La SC se presenta como una conversación en el marco de la telenovela costumbrista Café con aroma de mujer (capítulo 1, bloque 1, min. 7:22), sostenida entre Gaviota (locutora), joven recolectora de café y Aurelio (interlocutor), capataz de la hacienda Casablanca, la cual tiene lugar en la habitación que comparten madre e hija. Ambas acaban de llegar a la hacienda. Entre ellos se establece un diálogo en el que el locutor1 expresa con entusiasmo su interés por la lectura y la escritura, a partir de una mesa ubicada en el cuarto, con lo que el locutor2 no está de acuerdo por considerar que está muy mayor para estudiar. Con respecto al tema, la intención del locutor1 es manifestar la importancia que desempeñan la lectura y la escritura para sus planes de ascenso social y, con respecto a su interlocutor, persuadirlo sobre las ventajas de su interés por el estudio.

Como interlocutores se convoca la voz de los telespectadores de la telenovela, con el propósito de entretenerlos y atraerlos hacia los ideales educativos del locutor1.

Según los roles socio-institucionales, el locutor1 ocupa una posición asimétrica con respecto a su interlocutor debido a la relación jerárquica fuerte $(+\mathrm{J})$ que se establece entre ellos: recolectora-capataz, sin embargo, discursivamente se sitúa en un lugar superior y de más poder al exponer y defender su punto de vista con respecto a sus aspiraciones económicas relacionadas con la educación y lograr, finalmente, el reconocimiento de este que se siente inclinado a tratarla con más respeto ("doña").

Con respecto a las relaciones de fuerza social, la locutora, como poseedora de un saber que le concede legitimidad al discurso, defiende su postura ante sus interlocutores, lo cual le da un estatus de bien preparada e instruida (competente). En su discurso hay un reconocimiento explícito, directo y tajante de las bondades de la lectura y la escritura, el cual se constituye en un buen argumento con el que logra intimidar y convencer al capataz que se siente inclinado a darle la razón, mientras da vueltas insistentemente a su sombrero.

También, las manifestaciones de cortesía contribuyen a reforzar las relaciones de fuerza social entre los sujetos discursivos participantes. Es así como, en los enunciados citados, el uso del pronombre personal "usted", como forma de tratamiento, es utilizado de manera implícita por ambos interlocutores para dirigirse uno al otro -a excepción del segundo en el cual se hace explícita-, lo cual refuerza las relaciones de poder entre ellos, 
legitimadas en la SC, y pone en evidencia una forma de tratamiento particular utilizada por la cultura paisa como indicador de respeto, de distancia ${ }^{2}$.

\section{Situación de enunciación:}

La situación de enunciación es el espacio donde se construyen las imágenes valoradas de los sujetos discursivos y los diversos puntos de vista propuestos e integrados igualmente en el enunciado por el locutor. La identificación del enunciador responde a la pregunta sobre cuál es el punto de vista o los puntos de vista, propuestos en el enunciado. Así, en un mismo enunciado se puede, encontrar más de un enunciador, pues pueden realizarse más de dos puntos de vista, complementarios u opuestos. Hallamos, a este nivel de análisis, una polifonía enunciativa. La comprensión del enunciado consistirá en encontrar con cuál de los puntos de vista se identifica el locutor. Es en este espacio donde se construye la credibilidad del locutor-enunciador. Su análisis permite identificar las estrategias discursivas utilizadas para realizar la regulación social -control simbólicoentre los sujetos participantes en el género discursivo.

En este sentido, se observa cómo en el enunciado (1) se construye la imagen de un primer enunciador (E1), el cual emite su punto de vista a favor de crear las condiciones para el estudio al hacer alusión a una mesa que le sirve de instrumento para sus prácticas de lectura y escritura. Con esta expresión, E1 también construye la imagen de un enunciatario (Et1) como un aliado, haciéndolo partícipe de su propio orgullo por saber leer; asume que este la va a comprender y reconocer, aunque no posea la misma jerarquía social; lo considera como alguien que le va a dar la razón, que va a estar de acuerdo con ella en lo que respecta al estudio. Así mismo, se construye la imagen del tercero (el tema) como un aspecto de vital importancia para E1, pues relaciona el estudio con la idea de progreso y superación. En este enunciado se transforma la relación de asimetría entre las fuerzas sociales que lo componen hacia una relación más simétrica con los efectos de discurso de acercamiento que produce.

En el enunciado (2) se presenta la imagen de un segundo enunciador (E2), quien presuponiendo el significado del objeto aludido, replica en términos de desacuerdo restando importancia al interés mostrado por E1. La imagen de E2 se construye como un opositor al considerar que E1 está muy mayor para aprender, al tiempo que se construye la imagen de un enunciatario como una persona idealista, que cree aún que va a obtener a

2 En la cultura paisa es común encontrar formas de tratamiento como el vos y el usted, siendo utilizado el primero como indicador de confianza, de proximidad y el segundo como referente de respeto, de distancia (Calsamiglia y Tusón, 2002, p. 141), pero existen casos en que el uso se mezcla perdiéndose tal diferenciación, particularmente en las interacciones familiares y de amistad. 
su edad lo que desea. El punto de vista de E2, axiológicamente, no está de acuerdo con el punto de vista del enunciatario. El acento que $\mathrm{E} 2$ le imprime a la réplica es de incredulidad, la cual se corresponde con su manera de pensar, ya que cree que su interlocutora, debido a su edad, no debería seguir estudiando. Pero, a pesar de no constituirse en su aliado, exhibe una actitud de respeto hacia ella. La imagen que se crea del tercero también es negativa, en tanto se relaciona con la inconveniencia del estudio escolar en la edad adulta.

Al interrogarlo abiertamente en el enunciado (3) (“¿Le parece?”), el E1 contradice la opinión del E2 (la gente mayor no aprende). Con dicha expresión -muy paisa por cierto-, quiere decir que no considera que esté muy madura para el estudio, creando la imagen de un enunciatario incomprensivo, que no comprende las razones por las cuales estudia y una imagen positiva del tercero, en tanto considera que cualquier edad es conveniente para estudiar.

Sin embargo, el E2 se ratifica en su posición en el enunciado (4), con la expresión "pues sí" -también muy paisa-, manifestando, con algo de vacilación, que cree que la edad es un inconveniente para las pretensiones de estudio de E1.

En la réplica del $\mathrm{E} 2$ subyacen por lo menos tres puntos de vista: uno que le resta importancia a la educación en la edad adulta, otro que considera la educación de la mujer como innecesaria; y un tercero que desconoce los programas de validación y otras modalidades que el sistema educativo ha implementado para que los adultos accedan a la educación. La primera postura se fundamenta en una práctica cultural arraigada según la cual la escolaridad está relacionada con ciclos que inician en la infancia con la primaria y continúan en la pubertad y la adolescencia con la secundaria, por lo cual aprender a leer y escribir en la edad adulta no es bien visto social ni culturalmente. La segunda, tiene sus raíces en las disposiciones legales que regían en Colombia en la primera mitad del siglo XX en términos de educación, en las cuales no se contemplaba la educación de la mujer, por considerar que esta debía ocuparse del cuidado del hogar y la atención del marido y sus hijos. Este pensamiento estereotipado continúa perpetuándose en la sociedad colombiana, en particular en culturas que son eminentemente machistas. La tercera postura surge como respuesta a prácticas que se consideran naturalizadas y adecuadas por los campesinos en particular si son hombres.

Así mismo, en (4) el E2 construye la imagen de un enunciatario como una persona ilusa que, siendo mujer y adulta, aspira a continuar estudiando, ratificando su postura en el enunciado (2), al tiempo que se ratifica una imagen negativa del tercero con respecto al punto de vista del E1. 
En el enunciado (5) encontramos un locutor que, con una imagen de autoridad, presenta cuatro enunciadores: uno que no cree que leer y escribir sea necesario para ejercer el oficio de recolector de café; otro que valora la práctica de la lectura y la escritura como un medio que puede conducir al ascenso social; un tercero que considera que aprender a leer y escribir no es incompatible con la edad, y un cuarto que ve en el aprendizaje de la lectura y la escritura una forma de superación de la mujer.

En este enunciado, el punto de vista del E1 es negativo, en tanto se conforma y transige con un futuro precario e incierto. La imagen del enunciatario construida por el E1 es la de un sujeto que no sabe leer y escribir y, por lo tanto, está obligado a no ser más que un recolector de café. De igual manera, se construye una imagen negativa del tercero, según la cual, la lectura y la escritura no son necesarias para ser recolector de café.

El punto de vista del E2 es positivo y contradice la opinión de E1, pues considera la lectura y la escritura como la fórmula que lo llevará a obtener un mejor futuro, y con el cual coincide el locutor. Así mismo, este enunciador construye la imagen de un enunciatario comprensivo y solidario que ve en la educación una manera de escalar social y laboralmente, a la vez que construye una imagen positiva del tercero.

El punto de vista del E3 es negativo con respecto al del E1 (en contra) y positivo en relación con el de E2 (a favor), pues no cree que la edad sea un inconveniente para estudiar. Este enunciador crea, del enunciatario, la imagen de una persona mayor que tiene vocación por el estudio y de un tercero que considera que el estudio es compatible con la edad.

El punto de vista de E4, por su parte, es positivo; cree en las bondades del estudio para la superación de la mujer y construye del enunciatario la imagen de una mujer mayor que no encuentra obstáculos para el estudio, así como la imagen de un tercero que ve en el estudio un camino hacia la superación femenina.

En este enunciado se aprecian tres puntos de vista positivos: los de E2, E3 y E4, con los que se identifica el locutor y mediante los cuales pretende exaltar las bondades de la lectura y la escritura y defender su posición, lo cual es una estrategia del autor para valorizar el aspecto de la educación en la cultura que recrea. El ethos de superación mostrado por los enunciadores 2,3 y 4 es ratificado al exponerse con vehemencia las ventajas de la lecto-escritura. La postura asumida por estos enunciadores constituye, en la telenovela costumbrista, la forma en que el autor busca transformar las prácticas culturales estereotipadas que contribuyen al atraso y a la inequidad de género. 
De igual manera, el locutor exhibe un ethos de competencia, al utilizar en su defensa un razonamiento secuencial como el sorites chino $0^{3}$, modalidad explicativa, conclusiva y convincente, de fácil comprensión para su interlocutor, con lo cual muestra que sabe usar la palabra de manera argumentativa para exponer sus puntos de vista de manera clara y sin entrar en confrontación, lo que da cuenta también de su construcción como sujeto ético (virtuoso, sincero y honesto) y pragmático. Con la frase "Cómo la ve desde ahi”, otra expresión muy paisa, el locutor da por terminada su alocución, mostrando con ello que se siente orgulloso y satisfecho con su argumento. Mediante esta estrategia argumentativa utilizada (sorites chino), el locutor ostenta una autoridad persuasiva en tanto se muestra inteligente e informado (Plantin, 2009) con respecto a la educación (logos); se muestra superior ante $\mathrm{E} 1$ en términos de credibilidad ${ }^{4}$ y de respeto, construyendo así un ethos de credibilidad5.

Por lo demás, el discurso resulta ser muy persuasivo, en tanto contribuye a modificar el punto de vista de E1, quien en (6) finalmente asume un rol de aliado. Se aprecia en este enunciado una aproximación fuerte $(\mathrm{A}+)$ y una relación jerárquica social de simetría (J-) entre el E2, E3 y E4 y lo enunciado (tema valorado) en oposición al E1.

\section{Las tonalidades}

En la situación de enunciación también se encuentran las tonalidades, las cuales se revelan a través de imágenes que el autor del texto construye sobre los enunciadores por medio de los actos de habla. Martínez (2013) plantea tres tipos de tonalidades que componen el acto evaluativo responsable de la dinámica enunciativa y dan cuenta de las relaciones sociales, en términos de la valoración del punto de vista y del peso jerárquico que el locutor adjudica a cada uno de los participantes: tonalidad apreciativa, predictiva e intencional.

En los enunciados citados, se observa cómo en el primero, con una orientación positiva $(0+)$, mediante un acto de habla asertivo, se convoca una tonalidad intencional, en tanto el locutor construye una imagen de un enunciador responsable de lo que dice, cuya intención es afirmar y dejar constancia de su predilección por el estudio, con lo cual

3 Argumento de transitividad, organizado en secuencias y clasificado entre los argumentos cuasi-lógicos, los cuales buscan, mediante la explicación, parecer lógicos y lograr el convencimiento de un auditorio particular. Esta construcción discursiva requiere de un razonamiento secuencial muy estricto en su forma: el último término de la primera proposición, será el primero de la segunda, y así sucesivamente, hasta llegar a la conclusión. La conclusión del sorites está basada en un proceso de transitividad entre las ideas de cada proposición y constituyen una red de condiciones" (Martínez, 2005, pp. 184-185).

4 La credibilidad, según Aristóteles (1999, p. 309), es uno de los aspectos importantes de la persuasión y se construye sobre valores como la sensatez y la virtud (honradez).

5 Para Charaudeau (2009) el ethos de credibilidad está fundado en el discurso de la razón. 
se muestra como un ser virtuoso y moderado. Con respecto a la tonalidad predictiva, el E1 construye la imagen de un enunciatario como un ser solidario, mediante un acto de habla directivo, por medio del cual manifiesta complacencia en relación con su hábito por la lectura y la escritura y que se expresa en la búsqueda de un aliado al cual incita e interpela a partir de su proposición; apela al conocimiento que tiene el interlocutor sobre su persona y al tiempo que ha pasado en la hacienda y, particularmente, en ese cuarto y los usos que le ha dado a dicho objeto (mesa). En cuanto a la tonalidad apreciativa, se presenta una relación valorativa del enunciador con lo referido en términos de aprecio, de engrandecimiento, a través de actos de habla expresivos.

Sin embargo, en el enunciado (2), con una orientación negativa (0-) observamos que esta respuesta anticipada del primero hacia el segundo no es de aliado sino de oponente. El E2 manifiesta su desacuerdo con E1 a través de una crítica (acto declarativo de uso), haciendo una evaluación negativa sobre sus pretensiones de estudio. A la vez, mediante un acto de habla apelativo, con el cual refuta el punto de vista del E1, construye la imagen de un enunciatario como un ser idealista que cree que a su edad va a conseguir un futuro mejor por medio de la educación y, también, con el uso de actos de habla expresivos de crítica y desaprobación, construye una imagen negativa del tercero. Encontramos en este enunciado un distanciamiento débil (aproximación fuerte) entre el enunciador y el tercero, cuya relación indica una alianza entre los dos y una oposición con el enunciatario: enunciador-tercero (-D) >>aliados; enunciador-enunciatario (+D) > > oponentes.

En el enunciado (3), utilizando un acto declarativo (de uso), el E1 cuestiona el punto de vista del interlocutor, por lo cual lo interroga en tanto ella no se considera mayor para estudiar; además, con su interpelación (acto directivo) invoca la presencia de un enunciatario solidario y comprensivo. La imagen del tercero se construye a través de un acto expresivo positivo del enunciador por el cual considera que el estudio es apropiado a cualquier edad.

La réplica del E2 en (4), con orientación negativa, se constituye en un acto de habla asertivo, mediante el cual este reitera a E1 su posición de rechazo por el estudio en una persona mayor, y construye un enunciatario, cuya imagen es la de un adulto con pretensiones de estudiar, a través de actos apelativos implícitos, que lo minimizan y subvaloran. En este enunciado, se crea también una imagen negativa del tercero mediante actos expresivos que minimizan y desaprueban el estudio en una persona mayor.

Los actos de habla implícitos utilizados por los cuatro enunciadores en el enunciado (5) dan cuenta de la tonalidad intencional que toma el discurso y de la gran diversidad de relaciones sociales. Así, el E1 mediante un acto declarativo (de uso), rechaza la necesidad 
de la lectura y la escritura para el recolector, lo cual le da una imagen conformista. El E2 hace uso de dos actos de habla: uno, declarativo (de uso) para explicar las consecuencias negativas que tendría en su futuro el no practicar la lectura y la escritura, exhibiendo un ethos honesto y moderado; y otro, asertivo para reivindicar una posición de confianza y complacencia por el estudio para la obtención de un buen futuro, con lo cual muestra una imagen firme y segura. El E3, a partir de un acto de habla asertivo afirma que el estudio para una persona mayor no es un inconveniente sino que se adquiere a través del hábito, por lo que presenta una imagen de constante y dedicado. Así mismo, el E4 utiliza un acto asertivo para reivindicar que el hábito de estudiar puede contribuir a la superación de la mujer, exhibiendo un ethos seguro y competente.

Para dar razón de la tonalidad predictiva, esto es, lograr la adhesión de los enunciatarios en la búsqueda de la respuesta activa, cada uno de los enunciadores hace uso de procedimientos discursivos, también con actos de habla implícitos. Así, el E1 crea la imagen de un enunciatario analfabeta (recolector de café) mediante un acto de habla apelativo, por el cual refuta la necesidad que tiene este de saber leer y escribir. El E2, por su parte, construye la imagen de un enunciatario comprensivo y solidario a través de un acto propositivo (directivo), utilizando un argumento cuasi-lógico (sorites chino) que le sirve para explicar y ejemplificar su posición e inducirlo a comprender las bondades de la lectura y la escritura como fórmula de progreso y superación.

El enunciatario creado por el E3 corresponde a la imagen de una persona mayor que no considera su edad como un inconveniente para acceder al estudio, a partir de un acto de habla de aprobación, el cual utiliza también el E4 para presentar un enunciatario femenino y mayor que cree en el estudio como una forma de superación. Las relaciones sociales entre los enunciadores 2, 3, y 4 y los enunciatarios indican una alianza: enunciadorenunciatario (-D) >>aliados.

En cuanto a la tonalidad apreciativa, se encuentra que E1, mediante un acto de habla expresivo con orientación negativa, minimiza al tercero construyendo de este una imagen de reprobación y crítica, pues no considera que leer y escribir sean factores importantes para el desempeño de un recolector. Se halla acá un distanciamiento débil entre el enunciador y el enunciatario en una relación de alianza y un distanciamiento fuerte con el tercero en señal de oposición: enunciador-enunciatario (-D) >>aliados; enunciador-tercero $(+\mathrm{D})>>$ oponentes.

Por el contrario, los E2, E3 y E4, mediante actos expresivos con orientación positiva, manifiestan aprecio, reconocimiento y engrandecimiento hacia el tercero, estableciéndose 
entre enunciador, enunciatarios y tercero una alianza: enunciador-enunciatario-tercero (-D) >>aliados. En este enunciado, el locutor se identifica con estos tres puntos de vista.

En el enunciado (6), por su parte, se pone en juego una tonalidad intencional, en la cual el enunciador, mediante un acto comisivo, acepta, concuerda con la posición de E2, E3 y E4 en el enunciado (5), confirmando a través de la expresión de aceptación una alianza. El ethos de credibilidad exhibido por el locutor se pone en escena en (6) en tanto logra hacer cambiar de opinión a su interlocutor: "como diga doña Gaviota”. En este enunciado se construye la imagen del enunciador, el enunciatario y el tercero en alianza con los puntos de vista del E2, E3 y E4.

La tonalidad predictiva se muestra por medio de un acto directivo, por el cual el enunciatario aprueba los puntos de vista de E2, E3 y E4, conformando con el enunciador y el tercero una alianza.

En cuanto a la tonalidad apreciativa, el tercero se reconoce y acoge con respeto a partir de un acto expresivo positivo, con el cual se establece una alianza con el enunciador y el enunciatario.

\section{Dimensiones}

En Café con aroma de mujer, los sujetos discursivos se constituyen de manera integral a partir de tres dimensiones: ética (ethos), emotiva (pathos) y cognoscitiva (topos, ratio). Así, cada uno de ellos se construye en relación con el otro, permitiendo mostrar una cierta identidad de sí mismo, en tanto enunciador, enunciatario y tercero.

En los enunciados citados, el locutor, mediante sus palabras y argumentos, se construye a sí mismo como un sujeto respetuoso, honesto y sincero, y convoca al mismo tiempo la imagen del enunciatario como sujeto respetuoso y sincero, exhibiendo su ethos, o sea, su dimensión ética.

También, al exponer sus argumentos sobre las bondades que espera de su hábito por el estudio de la lectura y la escritura, el locutor utiliza una modalidad explicativa (sorites chino) para hacérselo entender de forma amable, agradable y solidaria a su interlocutor, por lo cual muestra su pathos, esto es, su dimensión emotiva. La imagen del enunciatario es la de un ser amable, agradable y solidario.

De la misma manera, el locutor demuestra ser un sujeto conocedor y competente que sabe argumentar y exponer con claridad lo que quiere con respecto a la educación. En el enunciado (5) construye la imagen de una mujer inteligente con aspiraciones de superación (E4), que no se conforma con el lugar social que ocupa y para demostrarlo 
intenta persuadir al interlocutor de sus metas para ascender social y laboralmente por medio del ejercicio de la lectura y la escritura, por medio de la utilización de un argumento persuasivo y convincente, actitud mediante la cual trasluce el ratio, o sea su dimensión racional, cognoscitiva.

\section{Conclusiones}

El análisis de la construcción del ethos del personaje de Gaviota a partir del tema de la educación, si bien representa una pequeña muestra de la investigación propuesta, permite concluir que las estrategias discursivas utilizadas en la telenovela costumbrista colombiana y plasmadas en una diversidad de ethos de los enunciadores pueden dar cuenta de la gran fuerza persuasiva que esta ejerce en la audiencia. Se considera que desde este personaje se movilizan imágenes asociadas a diversos ethos que rescatan aspectos tradicionales y costumbristas de la cultura paisa, así como otros que se pretenden valorizar como la educación de la mujer y el papel que desempeñan, la superación y la competencia en su ascenso social y laboral. Gaviota, como enunciador encarnado, cumple el papel de garante, fuente que legitima lo dicho. En este sentido, su carácter y corporalidad responden a representaciones sociales valorizadas o desvalorizadas (estereotipos) sobre los cuales se apoya la enunciación, las cuales pueden ser reforzadas o transformadas, según afirma Maingueneau (2009).

De igual manera, el análisis permitió observar claramente las voces y los diferentes puntos de vista expuestos por el locutor a través del personaje de Gaviota, así como el punto de vista con el cual se identifica el autor.

\section{Referencias bibliográficas}

Amossy, R. (1999). Images de soi dans le discours. La construction de l'ethos. Lausanne (Switzerland)-París: Delachaux et Niestlé S. A.

Aristóteles (1999). Retórica (Q. Racionero, trad.). Madrid: Gredos.

Bajtín, M. (2012). Problemas de la poética de Dostoievski. México: Fondo de Cultura Económica. Bajtín, M. (1982). Estética de la creación verbal. Bogotá: Siglo XXI.

Barthes, R. (1974). Investigaciones retóricas I. La antigua retórica. Buenos Aires: Tiempo Contemporáneo.

Calsamiglia, H., y Tusón, A. (2002). Las cosas del decir. Barcelona: Ariel. 
Charaudeau, P. (2009). La argumentación persuasiva. El ejemplo del discurso político. París: Université París-Nord 13.

Charaudeau, P., (1983). Langage et discours. Eléments de sémiolinguistique. París: Hachette.

Charaudeau, P. y Maingueneau, D. (2005). Diccionario de análisis del discurso. Buenos Aires: Amorrortu editores.

Ducrot, O. (1984). El decir y lo dicho. Buenos Aires: Hachette.

Maingueneau, D. (2009). Análisis de textos de comunicación. Buenos Aires: Nueva Visión.

Martínez, M. C. (2013). Los géneros desde una perspectiva socio-enunciativa. La noción de contexto integrado. Revista Latinoamericana de Estudios del Discurso (ALED), 13, 21-40.

Martínez, M. C. (2005). La argumentación en la Dinámica Enunciativa del Discurso y la construcción discursiva de la identidad de los sujetos. En Martínez, Didáctica del discurso (pp. 11-21). Cali: Cátedra UNESCO.

Martínez, M. C. (2001a). Análisis del discurso y práctica pedagógica. Barcelona-Buenos Aires: Homo Sapiens.

Martínez, M. C. (2001b). La dinámica enunciativa o la argumentación en la enunciación. En M. C. Martínez (Comp.) Aprendizaje de la argumentación razonada, Vol. 3 Cátedra UNESCO para la Lectura y la Escritura en América Latina-Universidad del Valle. Cali: Editorial Artes Gráficas.

Plantin, C. (2009). La personne comme ressource argumentative: ethos et résistance à l'autorité. (pp. 56-70). En : P. Charaudeau. Identités sociales et discursives du sujet parlant. París: L'Harmattan.

Soulez, G. (2009). Ethos, enunciación, medios. Semiótica del ethos. Comunicación y Medios, 19, 55-73. Universidad de París III.

Van Dijk, T. (2003). Ideología y discurso. Barcelona: Editorial Ariel. 